coteries (in this case, the Cambridge-based "society of the apostles") may engender that blend of vanity and arrogance that tempts people to believe they can mould the course of history by the secret exercise of their own wits. But in reality it is a shabby business, not merely damaging for those concerned when they are found out and for those whom they betray meanwhile, but for the conduct of normal relations between intellectual communities throughout the world.

The ubiquity of the spy has become an abomination. In many parts of the world, scientists and other intellectuals are habitually supposed to be potential agents when they travel abroad and may be suspected of potential treason when they return. Who knows how much of the present fragmentation between East and West of the science enterprise derives from the brooding suspicion of the intelligence agencies, vulnerable though they are themselves to infiltration, of the movement of people from one place to another?

That is merely one of the reasons why the time has come to put intelligence-gathering on a proper footing. Another, perhaps even more urgent, is that the repeated discovery of espionage networks in different places is a constant source of sourness in international relations. That intelligence services from time to time embark deliberately on subversive and even criminal activities, and must otherwise operate in some degree outside the normal rules of public accountability, is especially offensive. That many advanced societies must now put up with the indignity of self-imposed self-surveillance by telephone tapping and other such means is another part of the price that everybody pays for the dubious luxury of sustaining espionage. What can possibly be done to restrain not so much the curiosity of governments about what others do (which is legitimate), but the means by which they seek to satisfy that curiosity?

The best hope of progress must be technical, based on the use of electronic means of monitoring and analysing other people's electronic messages. This is the chief function of the National Security Agency in the United States and the General Communications Headquarters (GCHQ) in Britain, which in principle offer a means of learning about the military capabilities of other governments without requiring that people elsewhere should be actively disloyal. Is it entirely out of court that the major espionage governments should agree among themselves to rely on devices such as these wherever possible?(The fact that even organizations such as GCHQ may be penetrated by spies, as has been spectacularly demonstrated in Britain, is probably not nearly as relevant as it seems; those with secrets to hide should be able to guess which are at risk from listening posts and should plan accordingly.) Economic and political secrets, also common objectives of intelligence agencies, are less easily accessible to electronic surveillance, but are much more often within reach of an intelligent reading of other people's newspapers than the intelligence community would like to think. The underlying fallacy of much of what the intelligence services get up to is the assumption that each marginal element of information is almost priceless. Especially when the price already being paid includes a large element of self-imposed illiberality, this cannot be the case.

But an agreement to restrain mutual curiosity even if it were a formal convention, would hardly be sufficient by itself. Why not go further, and amend the Vienna Convention that regulates the use made of diplomatic missions in such a way as to deprive diplomats found guilty of espionage of the immunity from prosecution which they enjoy at present? There would be obvious difficulties is getting governments to agree that their nationals should be tried under other national laws, which vary enormously both in what they require as evidence and in penalties they impose but it should not be beyond the wit of well-intended people to develop a system of international criminal law to meet the need for an effective stick to beat the spies. The carrot, of course, is the benefit of the civility that would follow for the rest of us.

\section{Chernobyl made plain}

This is what the Soviet Union should say next week about the Chernobyl accident, and why.

NEXT week, there will be a gathering in Vienna, under the auspices of the International Atomic Energy Agency, to discuss the report prepared by the Soviet Union on the reasons for the accident at the Chernobyl reactor at the end of April. Only the sketchiest information about the Soviet document is as yet available (see opposite), and is certainly not sufficient in itself to satisfy legitimate curiosity elsewhere about the accident and its consequences. The chances are that even the full report will not do that: most official statements hurriedly put together leave unanswered questions that are best dealt with in the kinds of technical discussions arranged for next week, and in which the Soviet Union has agreed to take part. So far, so good.

That there is a legitimate curiosity in what happened at Chernobyl may seem to many in the Soviet Union to beg the question of the right by which people elsewhere inquire into strictly domestic matters, such as the arrangements for generating electricity. The simple answer, that the Chernobyl accident polluted the territory of other nations, is only part of the reason why some kind of explanation must be forthcoming, and by itself only requires from the Soviet Union an estimate of the amount and composition of the radioactivity released, an attempt to agree on estimates of the damage that may have been done with those affected and, if appropriate, an undertaking that there would be negotiations about compensation. Nothing has been heard, as yet, about formal demands for compensation, which would have to be raised through diplomatic channels by the governments believing themselves to have been injured, not at technical meetings such as that planned for next week. Meanwhile, the Soviet Union has implicitly acknowledged a wider legitimate interest in Chernobyl by its agreement to appear in Vienna.

A second explanation, but equally insufficient, for the Soviet decision to say more than the bare minimum is the need to head off future trouble with now-nervous neighbours. Long before the accident, there were protests about the siting of reactors near the borders between France and Belgium and between Czechoslovakia and Austria. So far, there has been relatively little complaint about Soviet reactor policy from the countries most at risk, those of the Warsaw Pact in Eastern Europe, but that may require special explanation. It is common prudence to take whatever steps are possible to anticipate and counter such anxieties. But the Soviet Union has gone further by agreeing to participate at Vienna and by doing some homework in advance.

What else can the world legitimately ask of the Soviet Union? Because even the Chernobyl accident might have been worse, people elsewhere have a right to be assured that the management of these complicated machines is conducted with the zealous regard for worked-out procedures which is the nuclear industry's standard boast on its own behalf. As things are shaping up, the Soviet Union plainly intends to meet this demand indirectly, by using an account of how laid-down procedures were not followed to suggest that the same need never happen again. But such an account will not suffice. Inevitably, and properly, questions will be raised at Vienna about the arrangements now in place for regulating the use of nuclear reactors. By what means are matters like this decided? Who are the people concerned? These will be painful questions for the Soviet Union to answer, but they cannot easily be ducked. Beyond them are the even larger issues in which external curiosity is legitimate: what can be gleaned over the years about the effects of radiation on people exposed to excessive doses of it? And what, in any case, is being done to safeguard or even monitor those at risk? There is no requirement in international law that one country must account to others for its care of its own people, but these exceptional circumstances require concessions even in that direction. 